\title{
The Needs of Learners for Fieldwork and Outdoor Activities in the Tourism Elective Course
}

\author{
Ilada Sarttatat \\ Tourism and Hotel programme, \\ Thepsatri Rajabhat University, \\ Lop Buri,Thailand \\ tud8363@gmail.com
}

\begin{abstract}
The objective of this research was to examine the needs of learners and one-day trekking for the elective course (Trekking and Adventure Tours). This mixed method research comprised both qualitative and quantitative approaches. Group discussion, participatory observation of trekking, a questionnaire on learners' satisfaction with fieldwork and outdoor activities were applied as research tools.

The findings illustrated that trekking should focus on group activity to strengthen unity among classmates. Regarding the one-day trekking location, learners were interested in a site with natural value where they would be unable to travel by themselves. The results of participatory observation for trekking showed that endemic plants and animals were found during trekking.

From the questionnaires, it was observed that the learners who went trekking were satisfied with the guide the most, followed by participation in fieldwork and outdoor activities, and recreation activities during trekking.
\end{abstract}

Keywords - fieldwork and outdoor activities, needs, tourism elective course

\section{INTRODUCTION}

Trekking and Adventure Tours is one of the elective courses included in the Tourism and Hotel curriculum (issued in 2011 and revised edition in 2016 of Tourism and Hotel programme, Faculty of Management Science). According to the university's curriculum regulation, all students are required to take elective courses to the value of 6 credits. Students can select Trekking and Adventure Tours for a value of 3 credits and course length spans 15 weeks in one semester.

This tourism course has become very popular with the chance to venture outside the classroom and visit areas of outstanding natural beauty. These field trips also allow students to bond emotionally and mentally with their colleagues through the direct learning approach. However, recently, numbers of students enrolling for this course have decreased due to both the instruction techniques of classroom lectures which focus on the role between teacher and student as teacher-centred instead of student-centred and also textbook learning by rote. There were no field trips or any outdoor activities planned during the last 15 weeks course. Assessment was conducted through tests and group reports; the students could search the answers from social media internet sites. Thus, students gained no direct experience or other cooperative skills and had no opportunities to appreciate and understand the intimate interconnecting relationships and interactions between nature and the environment. This did not relate to the title of the course as "Trekking and Adventure Tours" to train students to realize the benefits of eco-tourism through direct hands-on experiences.

Outdoor education involved cooperative learning method and it should be considered as an important and crucial part of the education programme to showcase positive behavioral impacts such as cooperation, leadership ability, self-confidence and problem-solving skills to resolve unusual and difficult situations [1]. Moreover, the needs of participants is notable to design for outdoor educational programme as it can be arranged in various places such as national parks, nature trails, waterways and forestry areas both in urban and rural settings due to it provides the challenges for personal growth, develop for specific skills in the natural environment[2]. Outdoor activities created well-being and resilience among youths and young adults [3].

Thus, promoting outdoor educational programs will offer students the chance to interact with nature and develop a passion for the great outdoors. Involvement in outdoor activities will improve and encourage students' environmental awareness[1]. Additionally, outdoor activities lead to fulfill 
psychological needs and valued psychological outcomes [4].

Our world exists as a tenuous ecological ecosystem that is finely balanced and easily disrupted and disturbed by the reckless and want on activities of human beings.

\section{LITERATURE REVIEW}

\section{A. Outdoor Activities}

Outdoor activities are an experiential learning method and it plays in important role to improve the participant's social interaction and develop their knowledge and specific skills in the natural environment [1]. Outdoor activities program which focused on recreation in a natural world environment can encourage the development of harmonious emotion and stimulate positive human interaction with nature and environment behavior [5]. There are eight experiences of nature which included entertainment and fun, a place for learning about ecological processes, a challenging environment involving fear and excitement and a threatened place with loss of species or natural areas of beauty [2]. The outdoor activities also related with the naturebased tourism (NBT) such as unmodified, undeveloped natural environment, and outside one's home [6].Outdoor activities lead to positive thought and emotions[1]. Moreover, outdoor recreational in the natural environment engages in motivation, environment behaviors of the participants [7]. Due to outdoor activities in nature-based bring environment awareness, social, and health benefit so outdoor activities in natural environment should be included in curriculum or education program [5] [8].

Young people nowadays think of nature as a place for outdoor recreation, adventure, fascination and fun. However, the perception of nature by the youth is very important. The youth are the future of our planet. Conservation of the remaining areas of natural beauty and a responsible behavioral outlook must be instilled in young people to preserve the heritage of planet Earth for further generations to also appreciate and enjoy.

\section{OBJECTIVES AND METHODS}

The needs of students for the tourism elective course (Trekking and Adventure Tours) were examined to determine appropriate outdoor activities.

The participants were comprised of $3^{\text {rd }}$ and $4^{\text {th }}$ year students at Thepsatri Rajabhat University, Lop Buri. Research was conducted following a mixed method approach comprising both qualitative and quantitative data collection. Group discussions, participatory observation of trekking and a questionnaire on student's satisfaction with fieldwork and outdoor activities were applied as research tools. The collected data were analyzed for content. Natural sites selected for the outdoor activities were the non hunting area of Hup Pa Tad Valley and the Samor Thong Hot Spring in Uthai Thani Province, Thailand. Research was conducted between August 2016 and November 2016.

\section{FINDINGS}

Results determined that the students considered a one-day trip outdoor activities model should consist of group events both on the bus travelling to the sites and also on arrival at the sites. In the study by O'Brien et al, outdoor activities which undertaken in nature could lead to give one's experience feelings of competence in environment and it can links to social competence in the group of participants [9]. The undergraduate's elective courses covered different programs and faculties including the Faculty of Management Science majoring in Tourism and Hotels, Computer Science and Faculty of Humanities and Social Sciences majoring in Education (English program) and Public Administration (Local Government). Hence, group activities on the bus were suggested to create recreational activities divided by different colors into each group. The purpose of the recreational activities on the bus was to encourage team unity and familiarity with other classmates.

For group activities at the sites, the students proposed trekking coordinated by each team to explore the cave and also bird watching, wildlife viewing and mountain climbing exercises. Group activities at the site were designed to strengthen team unity to better realise, understand and appreciate the beauty of nature and the natural habitat. Examples of these diverse activities in nature included wildlife watching, natural tree-naming puzzle games, cave climbing, treasure hunt in the forest, appreciating natural scenic views by taking photographs and camping for overnight trips. Outdoor fieldwork in the nature can gives the important chance to develop skill and knowledge of the participants and positively influence on the younger's attitudes, beliefs, and selfperceptions [9]. The students suggested that the outdoor activities should be supervised by a local tour guide who was knowledgeable and familiar with the forest area to supply information concerning the natural habitat of each wildlife species for the students to maximise study benefits and realise their ambitions for the trekking and adventure tour.

For the one-day outdoor activities trip, students were interested in learning about the natural area and appreciating the authentic and beautiful scenery, located in the pristine forest areas of the national park and also the Natural World Heritage Site. The elective students selected two places for their one-day trip for outdoor activities on the tourism course to take place.

The first location was Hup $\mathrm{Pa}$ Tad, an old forest area in a limestone valley located in the Tham Prathun Mountain non-hunting area, Lan Sak district, Uthai Thani Province in the central part of Thailand 
and near the Huai Kha Khaeng Wildlife Sanctuary, a World Heritage Site. The forest is home to ancient endemic plant species found only in Hup $\mathrm{Pa}$ Tad Valley. This old forest was once the Jurassic Park of Thailand.

The second was Jedkod Pong Kon Sao Waterfall located in Khao Sam Lan National Park in Saraburi Province in the central part of Thailand. Some students had previously visited the area and they reported that the waterfall also offered various other outdoor activities. This waterfall was only 85 kilometers or one and a half hours drive from the University.

However, all the students finally decided to go to Hup $\mathrm{Pa} \mathrm{Tad}$, the old forest area in the limestone valley located in the Tham Prathun Mountain non hunting area. They were interested in the ancient endemic plant species in this forest and the site was more remote and not so easy to reach. It was not a place that they would visit on their own and they were excited to travel here as a group activity.

Therefore, the researcher designed a one-day trip of outdoor activities to the Hup Pa Tad Valley for the students, following the results of group discussion. The researcher contacted the Forestry officer of Tham Prathun Mountain non hunting area to apply for permission to enter the forest and prepare the group activities at the site. Arrangements were also made to use the services of a local tour guide who was familiar and knowledge with this area. The distance from our host university, time of travelling and other remote tourist destinations nearby were also researched in detail.

Hup Pa Tad Valley is located 163 kilometers from our host university in the northern part of Thailand. The bus journey to Lop Buri Province takes about 2.20 hours or 4.40 hours per round trip. This natural site is located in a limestone valley. There is an existing and already created natural trail loop for tourists and visitors to explore which takes about 1-2 hours walk to complete. The valley is divided into three parts which include a limestone cave tunnel with stalactites and stalagmites in the limestone caves where chamois deer live. The entrance to the valley passes through a dark limestone cavern which is about 20 meters long. Then, there is a stone pathway which winds down into the bottom of the valley where the dominant endemic feather palm called "Arenga pinnata" and an endemic animal species "shocking pink millipede" (Desmoxytes purpurosea) can be seen on the nature trail. The millipede is mostly active during the rainy season. The first discovery of this small animal was publicized as the world's newest species of millipede in 2007. Sunlight filters through to the bottom of the valley floor only between the hours of eleven o'clock and one o'clock at the middle of the day. Thus, this area, although a nature trail, will always be wet and damp in the valley's closed ecosystem.

Another nearby remote tourist attraction is Pla Ra Limestone Mountain. There is a cave located close to the top of this mountain where 3,000-5,000 years old prehistorically color paintings have been found. This historical vestige indicates the cultural heritage of prehistoric human settlements in this area.

However, the limestone cliffs are very high and precipitous. Outdoor climbing activities are not possible during the limited period of a one-day trip due to lack of time. Visitors and tourists wishing to scale these cliffs must set off very early in the morning and allow at least three hours for this mountain climbing activity. They must also select a day when the weather is fine and there is no rain forecast. Another remote tourist attraction of this oneday trip is the natural Samor Thong Hot Spring. This is located 19 kilometers from the old forest site. The bus journey takes about 20 minutes while the Natural World Heritage Site is a further 50 kilometers.

Hence, the one-day trip programme will be designed for a half day at Pla Ra Mountain and Hup $\mathrm{Pa}$ Tad Valley in the non hunting area and the rest of the day will be spent at Samor Thong Hot Spring. The students will have the opportunity to learn more about another natural wonder such as hot springs at this second remote tourist attraction. The suggested one-day trip outdoor activities programme for the student elective course in November is shown as table below:

TABLE I. SCHEdULE OF ONE DAY TRIP

\begin{tabular}{|l|l|}
\hline \multicolumn{1}{|c|}{ Time } & \multicolumn{1}{c|}{ Schedule } \\
\hline 07.30 & Depart from host university \\
a.m. & Field trip at Pla Ra Mountain and Hup Pa Tad \\
\hline $\begin{array}{l}10.30 \\
\text { a.m. }\end{array}$ & Valley \\
\hline $\begin{array}{l}13.00 \\
\text { p.m. }\end{array}$ & Field trip at Samor Thong Hot Spring \\
\hline $\begin{array}{l}14.30 \\
\text { p.m. }\end{array}$ & Leave for host university \\
\hline $\begin{array}{l}17.30 \\
\text { p.m. }\end{array}$ & Arrive at host university \\
\hline
\end{tabular}

TABLE II. OUTDOOR ACTIVITIES PROGRAMME FOR GROUP Visit To Pla Ra Mountain And Hup Pa Tad Valley

\begin{tabular}{|l|l|l|}
\hline \multicolumn{1}{|c|}{$\begin{array}{c}\text { Group } \\
\text { No. }\end{array}$} & \multicolumn{1}{|c|}{ Theme } & \multicolumn{1}{c|}{ Content } \\
\hline 1 & Nature trail & $\begin{array}{l}\text { Photographing endemic } \\
\text { plants }\end{array}$ \\
\hline 2 & Bird watching & Introduction to birds \\
\hline 3 & $\begin{array}{l}\text { Butterfly } \\
\text { watching }\end{array}$ & Introduction to butterflies \\
\hline 4 & Wildlife watching & Introduction to wildlife \\
\hline 5 & Caves & $\begin{array}{l}\text { Introduction to caves } \\
\text { and the geology of the area }\end{array}$ \\
\hline
\end{tabular}


TABLE III. WORKSHEET FOR GROUP ACTIVITIES: PREPARATION OF EQUIPMENT FOR THE FIELD TRIP

\begin{tabular}{|l|l|l|}
\hline \multicolumn{1}{|c|}{ Theme } & Details & Purpose \\
\hline Clothing & & \\
\hline Equipment & & \\
\hline Food and drink & & \\
\hline Medicine & & \\
\hline
\end{tabular}

On the day of the field trip, group recreational activities on the bus included various kinds of games conducted by the students who were majoring in Tourism and Hotels. The purposes of these games were to break the ice and unite the students as one unit. Participants in the games won awards or souvenirs relating to the field trip equipment such as mosquito repellent cream, flashlight etc.

However, the weather was bad and the day before the field trip there was heavy rain all day. Therefore, mountain climbing at Pla Ra Mountain was cancelled. We also arrived at the site one hour later than scheduled. Moreover, some students were overweight and the local forest tour guide decided that their health condition was not suitable for climbing mountains in wet and hot weather. Outdoor thermal in natural environment (e.g. sunlight, temperature, humidity) correlates to participant's behaviors and the cooler thermal environment bring better behavioral benefits [8]. Thus, the field trip only focused on outdoor activities at Hup Pa Tad Valley (half-day) and the hot spring (half-day).

Group activities involving trekking participation at the natural site showed that the students enjoyed communing with nature as a team. They first found and then took photos of the endemic plants and animals during their trekking adventure. Each group activity lasted about one or two hours. Before entering the valley, they were introduced to the site and shared the experience and knowledge of the local forest guide who also works as a forest official. They received information concerning the endemic plants and animals and details regarding the geology of the valley. This provided them with useful information about the sites. The students reported the various kinds of endemic plants and animals that they had seen in the valley as shown in table 4 .

TABLE IV. Plants AND ANIMALS ReCORDED DURING OUTDOOR ACTIVITIES IN HuP PA TAD VALLEY

\begin{tabular}{|l|l|l|}
\hline \multicolumn{1}{|c|}{ Endemic plant } & \multicolumn{1}{|c|}{ Endemic animal } & Special area \\
\hline Arenga pinnata & $\begin{array}{l}\text { Desmoxytes } \\
\text { purpurosea }\end{array}$ & $\begin{array}{l}\text { Nature trail, } \\
\text { Hup Pa Tad } \\
\text { Valley }\end{array}$ \\
\hline $\begin{array}{l}\text { Balanophora } \\
\text { fungosa J.R. \& }\end{array}$ & Birds(wild pigeon) & \\
\hline
\end{tabular}

\begin{tabular}{|c|c|c|}
\hline \multicolumn{2}{|l|}{ G. Forst } & \\
\hline $\begin{array}{l}\text { Mushroom } \\
\text { Pycnoporus } \\
\text { cinnabarinus }\end{array}$ & Land turtle & \\
\hline \multirow[t]{3}{*}{ Ficus hispida L.f. } & $\begin{array}{l}\text { Monkeys } \\
\text { (Long-tailed } \\
\text { Macaque) }\end{array}$ & \\
\hline & $\begin{array}{l}\text { Snakes } \\
\text { (Reticulated python) }\end{array}$ & \\
\hline & $\begin{array}{l}\text { Capricornis } \\
\text { sumatraensis } \\
\text { (footprints) }\end{array}$ & $\begin{array}{l}\text { Limestone } \\
\text { caves }\end{array}$ \\
\hline
\end{tabular}

Results of these participatory observations showed that outdoor group activities encouraged teamwork for group learning in the natural environment. The group learning can provide the positive impact on the learner's attitude change and skill, self-learning, and more proactive [1].

Then, we went to Samor Thong Hot Spring located at the central island of the Huay Khun Kaew Reservoir. This natural hot spring is caused by an underground heated water source and falls under the supervision of Samor Thong local government authority. The spring water temperature ranges between $40-80^{\circ} \mathrm{C}$. Participants learned about the origins, significance and benefits of hot springs.

After ending the field trip, questionnaires were completed to judge the satisfaction levels of the students. Respondents were female $53.12 \%$ and $46.88 \%$ male. Most were $3^{\text {rd }}$ year students aged between 20-22 years old. Average age was 21 (43.75\% of the group).

The questionnaire used a 5-point Likert scale to assess the responses regarding each item. Results indicated that participants had sufficient background knowledge about the natural sites and outdoor activities enjoyment was medium After the trip, their understanding concerning the natural sites and outdoor activities increased. Students who participated in the trekking activities were satisfied with the guide, followed by participation in fieldwork and outdoor activities and recreation activities during trekking. However, respondents were disappointed with the outdoor activities at Hup Pa Tad Valley and Samor Thong Hot Spring as the excessive travelling time at four hours from the host university to the natural site was too long to return in one day. They had to get up very early and when they reached the site they were tired and could not trek up the Pla Ra Mountain.

They could not engage together in various outdoor activities at the two sites due to limited time available. The period allocated to perform outdoor activities was too short. They suggested that it would be better to stay one night at the natural site so they could have more time to learn about and be surrounded by nature. 


\section{CONCLUSION}

The next research regarding a one-day trip of outdoor activities for students should select a natural site which was located closer to the host university, Uncontrollable factors such as weather conditions, time to travel, programme goal and unforeseen events can occur at any time. These make the situation uncertain concerning students' perceptions and matching their needs. Thus, success in designing outdoor activities to match students' needs of the tourism elective course should leave nothing to chance. Both organizers and participants of outdoor activities should remain aware of this statement at all times.

\section{REFERENCES}

[1] M. T. Harun, and N. Salamuddin, "Cultivating personality development through outdoor education programme: the Malaysia experience," Building and Environment, vol. 103, 2016 , 10.1016/j.buildenv.2016.03.029. pp. 238-249. DOI:

[2] K. S. Lekies, G. Yost, and J. Rode, "Urban youth's experiences of nature: implications for outdoor adventure recreation," and Tourism, vol. 9, 2015, Journal of Outdoor Recreation pp.1-10. DOI:

[3] M. Mutz, and J. Muller, "Mental health benefits of outdoor adventures: results from two pilot studies," Journal of Adolescence, vol. 49, 2016, pp. 105-114. DOI: 0.1016/j.adolescence.2016.03.009.
[4] P. J. Fix, J. Carroll, and A.M. Harrington, " Visitor experiences across recreation settings: a management or measurement issue?" Journal of Outdoor Recreation and Tourism, vol. 3-4, 2013, pp. 28-35. DOI: 10.1016/j.jort.2013.09.003.

[5] A. Junot, Y. Paquet, and C. Martin-Krumm, " Passion for outdoor activities and environmental behaviors: A look at emotions related to passionate activities," Journal of Environmental Psychology, vol. 53, 2017, pp. 177-184. DOI: 10.1016/j.jenvp.2017.07.011.

[6] L. Margaryan, and P. Fredman, " Bridging outdoor recreation and nature-based tourism in the commercial context: Insights from the Swedish service providers," Journal of Outdoor Recreation and Tourism, vol. 17, 2017, pp. 84-92 .DOI: 10.1016/j.jort.2017.01.003.

[7] N. Kil, S. M. Holland, and T. V. Stein, "Structural relationship between environmental attitudes, recreation motivations, and environmentally responsible behaviors," Journal of Outdoor Recreation and Tourism, vol. 7-8, 2014, pp. $16-25$. 10.1016/j/jort.2014.09.010.

[8] J. Huang, C. Zhou, Y. Zhou, L. Xu, and Y. Jiang, “ Outdoor thermal environments and activities in open space: an experiment study in humid subtropical climates," Building and Environment vol. 103, DOI: 10.1016/j.buildenv.2016.03.029.

[9] L. O'Brien, et al, “ Outdoor education, life long learning and skills development in Woodlands and Green Spaces: the potential links to health and well-Being," in K. Nilsson et al. (eds.),

[10] Forests, Trees and Human Health, 2011, Springer Dordrecht. DOI: 10.1007/978-90-481-9806-1_12 